\title{
1,2,3-triazole functionalized polystyrene and perdeuterated polystyrene chelating latexes
}

Hadjira Lahmar, ${ }^{1}$ Ibrahim Badr, ${ }^{2}$ Chariya Kaewsaneha, ${ }^{2,3}$ Abdelhamid Elaissari, ${ }^{2}$ Salima SaidiBesbes $^{* 1}$

${ }^{1}$ Université Oran1, Laboratoire de Synthèse Organique Appliquée (LSOA), Département de Chimie, Faculté des Sciences Exactes et Appliquées, Bp 1524 El Mnaouer, 31000 Oran, Algeria.

${ }^{2}$ Univ Lyon, University Claude Bernard Lyon-1, CNRS, LAGEP-UMR 5007, F-69622 Lyon, France

3 School of Bio-Chemical Engineering and Technology, Sirindhorn International Institute of Technology (SIIT), Thammasat University, PathumThani 12121, Thailand

*Corresponding Author: *saidi.salima@univ-oran1.dz

\begin{abstract}
Emulsifier-free polystyrene latexes with immobilized triazolic residues have been prepared by batch emulsion copolymerization of styrene with 1,2,3-triazole-based acrylic monomers containing diethylene or triethylene glycol monomethyl ether groups DEGTz and TEGTz, respectively. The effect of monomer structure and concentration on polymerization conversion, particle size and morphology was investigated. Particle composition was also evidenced by ${ }^{1} \mathrm{H}-\mathrm{NMR}$ analysis. It was found that DEGTz monomer with the shorter pegylated chain allows the formation of the smaller particles with a better control of polytriazole water soluble oligomers formation.

DEGTz and TEGTz were then used in batch and shot growth polymerization of styrene-d8 in the aim to highlight the effect of deuterium isotope substitution. It was shown that the use of deuterated styrene significantly impacts the polymerization conversion as well as particle size and shape regardless of the monomer structure. Shot growth process disadvantaged the copolymer particle formation in favour of obtaining water soluble polymers. This was confirmed from NMR study and from the large values of surface charge density of latexes obtained from electrophoretic mobility.
\end{abstract}

\section{Keywords}

1,2,3-triazole; chelating monomer; emulsion polymerization; perdeuterated polystyrene; shotgrowth process. 


\section{INTRODUCTION}

In recent years, the use of polymer supports for immobilization of several ligands, catalysis and probes has generated great interest for organic synthesis, biomedical and environmental applications [1-2]. The activity of attached reagent is directly tied to its accessibility to the active sites and is often limited due the burying of these sites inside the cross-linked supports. In this context, the development of novel supported polymers with improved selectivity, efficiency, stability, reaction kinetic, thermal and mechanical properties is highly requested for products that fulfill customers' requirements.

Several methods have been used to access to such polymers with controlled functionality, size and size distribution such as emulsion polymerization, suspension polymerization, precipitation polymerization or atom transfer radical (ATRP) and reversible addition-fragmentation chain transfer (RAFT) polymerization techniques [3-5]. Micro- and submicrosized particles with a broad variety of morphologies can be obtained that exhibit high surface area to volume ratio helpful for interaction with actives sites. Among these methods, emulsion polymerization has gained its popularity as an easy production process because of its numerous outstanding advantageous as good temperature control, high polymerization rate, low viscosity of the final dispersions and easy removal of unreacted monomers. Furthermore, the use of emulsifier-free process allows to prevent the contamination of the final products by emulsifier and consequently the latex properties deterioration due to the surfactant migration particularly for coating and adhesive applications [6-7].

For metal remediation applications, various low-molecular ligands have been immobilized on polymer matrix. Among them those containing nitrogen, oxygen and phosphorus atoms received particular attention due to their strong affinity for divalent transition metal cations. The most common ligands include heterocyclic amines, amidoximes, dithizone, hydroxamic acid, crown ethers, phenolics and phosphorus-based ligands [8-9]. The Incorporation of these ligands can be ensured onto polymer particles through different strategies as physical adsorption of chelating polymers on polymer latex supports [10], functionalization of preformed latex particles bearing suitable reactive functions and spacers with ligand moieties [11-13] or copolymerization of polymer particles with functional monomers containing the chelating functions [14]. 
This last strategy, more suitable and versatile, that enables tailoring the particles surface composition by simple variation of experimental conditions, was indisputably less studied probably due to the difficulty of designing suitable functional monomer using simple and efficient synthetic pathways.

The first objective of the present study was to investigate the soap-free emulsion polymerization of styrene in the presence of two chelating monomers, 1-((diethyleneglycol) methylether)-1H-1,2,3-triazol-4-yl methylacrylate (DEGTz) and 1-((triethyleneglycol) methylether)-1H-1,2,3-triazol-4-yl methylacrylate (TEGTz) by batch process. These monomers were designed and synthesized because oligoethylene glycol moieties and 1,2,3triazole heterocycle constitutes multiple complexation sites of metal ions. The colloidal properties and surface composition of latex particles were examined using different technics as ${ }^{1} \mathrm{H}-\mathrm{NMR}$, DLS and TEM analyses.

In a second time, batch and shot growth polymerization reactions of these monomers were carried out by using perdeuterated styrene (styrene d8) as a comonomer in the aim to highlight the influence of deuterium substitution on the size, morphology and composition of final latex particles. Although recent studies show that the physical properties of polymers can be affected by deuteration [15-17], very few data on isotope effects in radical reactions have been reported.

\section{EXPERIMENTAL PROCEDURE}

\subsection{Methods}

${ }^{1} \mathrm{H}$ and ${ }^{13} \mathrm{C}-\mathrm{NMR}$ spectra were recorded on a Brucker $300 \mathrm{MHz}$ spectrometer (Brucker, Wissembourg, France). Tetramethylsilane was used as an internal reference for chemical shifts. Column chromatography separations were carried out using E-Merck silica gel (Kieselgel 60,230-400 mesh) as the stationary phase. Thin-layer chromatographies were performed on aluminum plates precoated with Merck silica gel 60F254 and visualized by means of ultraviolet fluorescence quenching.

\subsection{Materials}

Diethylene glycol methyl ether, triethylene glycol methyl ether, 4-toluenesulfonyl Chloride (99.5\%), triethylamine (99\%), sodium azide, propargyl alcohol, potassium persulfate initiator KPS (+99\%) were purchased from Sigma-Aldrich (Tlemcen-Algeria) and used without 
further purification. The solvents were of commercial grade quality and were dried and distilled before use.

Styrene-d8 (98 atom\% D) stabilized with 4-t butylcatechol was purchased from Aldrich (Germany). Styrene 99\%, stabilized with 10-15 ppm catechol was purchased from Alfa Aesar. They were purified by washing with an aqueous solution of $\mathrm{NaOH} 1 \mathrm{M}$ to remove inhibitor then three times with deionized water and stored at $-20^{\circ} \mathrm{C}$. In all polymerization procedures, deionized water was used.

\subsection{Synthesis}

\subsubsection{Synthesis of O-tosyl-(ethyleneglycol) methyletherderivatives (1a-b)}

In a typical procedure, $(0.083 \mathrm{~mol})$ of diethylene glycol methyl ether or triethylene glycol methyl ether was added to a solution of (9.54 g, $2.8 \mathrm{eq})$ sodium hydroxide dissolved in $50 \mathrm{~mL}$ of a mixture of water/ tetrahydrofurane 1/1. The mixture was placed in an ice bath, and (15.82 $\mathrm{g}, 0.083 \mathrm{~mol})$ of 4-toluene sulfonyl chloride dissolved in $50 \mathrm{~mL}$ of tetrahydrofuran were added dropwise during $2 \mathrm{~h}$. The stirring was maintained for 2 hours at $0^{\circ} \mathrm{C}$ then the reaction mixture was poured into cold water and extracted three times with dichloromethane. The organic layers were dried over magnesium sulphate. The products were obtained as yellow oil after solvent evaporation and used without further purification.

1a:Yield (90\%), ${ }^{1} \mathrm{H}$ NMR (300 MHz, $\left.\mathrm{CDCl}_{3}\right): \delta(\mathrm{ppm}) 2.39$ (s, 3H, $\underline{\mathrm{CH}}_{3}$ ), 3.29 (s, 3H, OC$\underline{H}_{3}$ ), $3.42\left(\mathrm{t}, 2 \mathrm{H}, \mathrm{CH}_{3} \mathrm{OCH}_{2},{ }^{3} \mathrm{~J}=5.44 \mathrm{~Hz}\right), 3.51\left(\mathrm{t}, 2 \mathrm{H}, \mathrm{CH}_{3} \mathrm{OCH}_{2} \mathrm{CH}_{2},{ }^{3} \mathrm{~J}=5.02 \mathrm{~Hz}\right), 3.63(\mathrm{t}, 2 \mathrm{H}$, $\left.\mathrm{OCH}_{2} \mathrm{CH}_{2} \mathrm{OSO}_{2},{ }^{3} \mathrm{~J}=4.88 \mathrm{~Hz}\right), 4.11\left(\mathrm{t}, 2 \mathrm{H}, \mathrm{CH}_{2} \mathrm{OSO}_{2},{ }^{3} \mathrm{~J}=4.88 \mathrm{~Hz}\right), 7.30\left(\mathrm{~d}, 2 \mathrm{H}, \mathrm{Ar}-\mathrm{H},{ }^{3} \mathrm{~J}=\right.$ 8.34Hz), $7.74\left(\mathrm{~d}, 2 \mathrm{H}, \mathrm{Ar}-\mathrm{H},{ }^{3} \mathrm{~J}=8.34 \mathrm{~Hz}\right) .{ }^{13} \mathrm{C}$ NMR $\left(75 \mathrm{MHz}, \mathrm{CDCl}_{3}\right) \delta(\mathrm{ppm}) 21.43\left(\mathrm{CH}_{3}\right), 58.75$ $\left(\mathrm{OCH}_{3}\right), \quad 68.46 \quad\left(\underline{\mathrm{CH}}_{2} \mathrm{SO}_{2}\right), \quad 69.32 \quad\left(\mathrm{OCH}_{2} \mathrm{CH}_{2} \mathrm{SO}_{2}\right), \quad 70.37 \quad\left(\mathrm{CH}_{3} \mathrm{OCH}_{2} \underline{C H}_{2} \mathrm{O}\right), 71.60$ $\left(\mathrm{CH}_{3} \mathrm{OCH}_{2}\right), 127.79$ (Ar), 129.81(Ar), 132.76 (Ar), 144.84 (Ar).

1b: Yield (94\%), $\mathrm{H}^{1} \mathrm{NMR}\left(300 \mathrm{MHz}, \mathrm{CDCl}_{3}\right) \delta(\mathrm{ppm}): 2.30$ (s, 3H, $\left.\underline{\mathrm{H}}_{3}\right), 3.21$ (s, $3 \mathrm{H}$ , $\left.\mathrm{OCH}_{3}\right), 3.38\left(\mathrm{t}, 2 \mathrm{H}, \mathrm{CH}_{3} \mathrm{OCH}_{2},{ }^{3} \mathrm{~J}=5.32 \mathrm{~Hz}\right), 3.46\left(\mathrm{~m}, 6 \mathrm{H}, \mathrm{CH}_{3} \mathrm{OCH}_{2} \underline{\mathrm{CH}}_{2} \mathrm{OCH}_{2} \underline{\mathrm{CH}}_{2} \mathrm{O}\right), 3.54$ $\left(\mathrm{t}, 2 \mathrm{H}, \mathrm{OC}_{2} \mathrm{CH}_{2} \mathrm{OSO}_{2},{ }^{3} \mathrm{~J}=4.84 \mathrm{~Hz}\right), 4.02\left(\mathrm{t}, 2 \mathrm{H}, \mathrm{CH}_{2} \mathrm{OSO}_{2},{ }^{3} \mathrm{~J}=4.84 \mathrm{~Hz}\right), 7.22(\mathrm{~d}, 2 \mathrm{H}, \mathrm{Ar}-\mathrm{H}$, $\left.{ }^{3} \mathrm{~J}=8.32 \mathrm{~Hz}\right), 7.65\left(\mathrm{~d}, 2 \mathrm{H}, \mathrm{Ar}-\mathrm{H},{ }^{3} \mathrm{~J}=8.32 \mathrm{~Hz}\right) \cdot{ }^{13} \mathrm{C} \mathrm{NMR}\left(75 \mathrm{MHz}, \mathrm{CDCl}_{3}\right) \delta(\mathrm{ppm}) 21.45$ $\left(\underline{\mathrm{CH}_{3}}\right), 58.77\left(\mathrm{OCH}_{3}\right), 68.46\left(\underline{\mathrm{CH}}_{2} \mathrm{SO}_{2}\right), 69.28\left(\mathrm{OCH}_{2} \mathrm{CH}_{2} \mathrm{SO}_{2}\right), 70.31\left(\mathrm{CH}_{3} \mathrm{OCH}_{2} \underline{C H}_{2} \mathrm{O}\right)$, $70.49\left(\mathrm{CH}_{3} \mathrm{OCH}_{2} \mathrm{CH}_{2} \mathrm{OCH}_{2} \underline{\mathrm{CH}}_{2} \mathrm{O}\right), 71.72\left(\mathrm{CH}_{3} \mathrm{OCH}_{2}\right), 127.78(\mathrm{Ar}), 129.78(\mathrm{Ar}), 132.83$ (Ar), 144.78 (Ar).

\subsubsection{Synthesis ofazido-(ethyleneglycol) methylether derivatives (2a-b)}


O-tosyl-(ethyleneglycol) methylether derivative (1a-b) (0.021 mol) was added to a solution of sodium azide $(2.73 \mathrm{~g}, 0.042 \mathrm{~mol})$ dissolved in $10 \mathrm{~mL}$ of dimethylformamide. The reaction was stirred at $70{ }^{\circ} \mathrm{C}$ for $48 \mathrm{~h}$ under nitrogen atmosphere. The solution was extracted three times with dichloromethane and the combined organic phases were washed with water then dried under anhydrous magnesium sulphate. Solvent evaporation affords an orange liquid.

2a: Yield (94\%), $\mathrm{H}^{1} \mathrm{NMR}\left(300 \mathrm{MHz}, \mathrm{CDCl}_{3}\right) \delta(\mathrm{ppm}) 3.16\left(\mathrm{~s}, 3 \mathrm{H}, \mathrm{OCH}_{3}\right), 3.20\left(\mathrm{t}, 2 \mathrm{H}, \mathrm{CH}_{2} \mathrm{~N}_{3}\right.$, $\left.{ }^{3} \mathrm{~J}=5.22 \mathrm{~Hz}\right), 3.36\left(\mathrm{t}, 2 \mathrm{H}, \mathrm{OCH}_{2} \mathrm{CH}_{2} \mathrm{~N}_{3},{ }^{3} \mathrm{~J}=5.22 \mathrm{~Hz}\right), 3.55\left(\mathrm{~m}, 4 \mathrm{H}, \mathrm{CH}_{3} \mathrm{OC}_{2} \underline{\mathrm{C}}_{2} \mathrm{O}\right) .{ }^{13} \mathrm{C} \mathrm{NMR}$ $\left(75 \mathrm{MHz}, \mathrm{CDCl}_{3}\right) \delta(\mathrm{ppm}) 50.49\left(\underline{\mathrm{CH}}_{2} \mathrm{~N}_{3}\right), 58.86\left(\mathrm{OC}_{3}\right), 69.88\left(\mathrm{CH}_{3} \mathrm{OCH}_{2} \mathrm{CH}_{2} \mathrm{O}\right), 70.42$ $\left(\mathrm{O}_{\underline{C}} \mathrm{CH}_{2} \mathrm{~N}_{3}\right), 71.81\left(\mathrm{CH}_{3} \mathrm{OCH}_{2}\right)$.

2b: Yield (92\%), $\mathrm{H}^{1} \mathrm{NMR}\left(300 \mathrm{MHz}, \mathrm{CDCl}_{3}\right) \delta(\mathrm{ppm}) 3.27\left(\mathrm{~s}, 3 \mathrm{H}, \mathrm{OC}_{3}\right), 3.29$ (d, 2H, $\left.\mathrm{CH}_{2} \mathrm{~N}_{3},{ }^{3} \mathrm{~J}=5.26 \mathrm{~Hz}\right), \quad 3.45 \quad\left(\mathrm{t}, \quad 2 \mathrm{H}, \quad \mathrm{OCH}_{2} \mathrm{CH}_{2} \mathrm{~N}_{3},{ }^{3} \mathrm{~J}=5.26 \mathrm{~Hz}\right), 3.56 \quad(\mathrm{~m}, \quad 8 \mathrm{H}$, $\left.\mathrm{CH}_{3} \mathrm{O}\left(\mathrm{CH}_{2} \mathrm{CH}_{2} \mathrm{O}\right)_{2}\right) .{ }^{13} \mathrm{C}$ NMR $\left(75 \mathrm{MHz}, \mathrm{CDCl}_{3}\right) \delta(\mathrm{ppm}) 50.55\left(\underline{\mathrm{CH}}_{2} \mathrm{~N}_{3}\right), 58.84\left(\mathrm{OCH}_{3}\right), 69.89$ $\left(\mathrm{OCH}_{2} \mathrm{CH}_{2} \mathrm{~N}_{3}\right), \quad 70.43 \quad\left(\mathrm{CH}_{3} \mathrm{OCH}_{2} \underline{C H}_{2}\right), \quad 70.49 \quad\left(\mathrm{OCH}_{2} \mathrm{CH}_{2} \mathrm{O}\right), 70.54 \quad\left(\mathrm{OCH}_{2} \mathrm{CH}_{2} \mathrm{O}\right)$, $71.79\left(\mathrm{CH}_{3} \mathrm{OCH}_{2}\right)$.

\subsubsection{Synthesis of 1,2,3-triazole derivatives (3a-b)}

Azido-(ethyleneglycol) methylether derivative (2a-b) (0.013 mol) was added to a solution containing (0.72 g, $0.013 \mathrm{~mol})$ of propargylalcohol, $(0.25 \mathrm{~g}, 0.0013 \mathrm{~mol})$ of copper iodide and few drops of triethylamine $\left(\mathrm{Et}_{3} \mathrm{~N}\right)$ in $20 \mathrm{~mL}$ of a mixture of water/Ethanol (1/1). The reaction mixture was heated at $70{ }^{\circ} \mathrm{C}$ for $48 \mathrm{~h}$. The solution is then extracted three times with dichloromethane and the organic phases are dried under magnesium sulfate. After solvent evaporation, the product is obtained as oil.

3a: Yield (95\%), $\mathrm{H}^{1} \mathrm{NMR}\left(300 \mathrm{MHz}, \mathrm{CDCl}_{3}\right) \delta(\mathrm{ppm}) 3.27$ (s, 3H, OC$\left.\underline{H}_{3}\right), 3.44$ (t, $2 \mathrm{H}$, $\left.\mathrm{CH}_{3} \mathrm{OC}_{2},{ }^{3} \mathrm{~J}=5.50 \mathrm{~Hz}\right), 3.51\left(\mathrm{t}, 2 \mathrm{H}, \mathrm{CH}_{3} \mathrm{OCH}_{2} \mathrm{CH}_{2} \mathrm{O},{ }^{3} \mathrm{~J}=5.50 \mathrm{~Hz}\right), 3.78(\mathrm{t}, 2 \mathrm{H}$, $\left.\mathrm{OC}_{2} \mathrm{CH}_{2} \mathrm{~N},{ }^{3} \mathrm{~J}=4.96 \mathrm{~Hz}\right), 4.46\left(\mathrm{t}, 2 \mathrm{H}, \mathrm{CH}_{2} \mathrm{~N},{ }^{3} \mathrm{~J}=4.96 \mathrm{~Hz}\right), 4.66\left(\mathrm{~s}, 2 \mathrm{H}, \mathrm{CH}_{2} \mathrm{OH}\right), 7.72(\mathrm{~s}$, $1 \mathrm{H}$, triazole). ${ }^{13} \mathrm{C}$ NMR $\left(75 \mathrm{MHz}, \mathrm{CDCl}_{3}\right) \delta(\mathrm{ppm}) \quad 50.49\left(\underline{\mathrm{CH}}_{2} \mathrm{~N}\right), 55.74\left(\underline{\mathrm{CH}}_{2} \mathrm{OH}\right), 58.85$ $\left(\mathrm{O}_{\underline{C}} H_{3}\right), 69.32\left(\mathrm{OCH}_{2} \mathrm{CH}_{2} \mathrm{~N}\right), 70.30\left(\mathrm{OCH}_{2} \underline{\mathrm{CH}}_{2} \mathrm{O}\right), 71.61\left(\mathrm{CH}_{3} \mathrm{OCH}_{2}\right), 123.33\left(\underline{\mathrm{CH}}_{\text {triazole }}\right)$, 142.1( $\left.\underline{\mathrm{C}}_{\text {triazole }}\right)$.

3b:Yield (90\%), $\mathrm{H}^{1} \mathrm{NMR}\left(300 \mathrm{MHz}, \mathrm{CDCl}_{3}\right) \delta(\mathrm{ppm}) 3.33\left(\mathrm{~s}, 3 \mathrm{H}, \mathrm{OC}_{3}\right), 3.50(\mathrm{t}, 2 \mathrm{H}$, $\left.\mathrm{CH}_{3} \mathrm{OC} \underline{H}_{2},{ }^{3} \mathrm{~J}=5.34 \mathrm{~Hz}\right), 3.55\left(\mathrm{~m}, 6 \mathrm{H}, \mathrm{CH}_{3} \mathrm{OCH}_{2} \underline{\mathrm{CH}}_{2} \mathrm{OC}_{2} \underline{\mathrm{C}}_{2} \mathrm{O}\right), 3.82\left(\mathrm{t}, 2 \mathrm{H}, \mathrm{OC}_{2} \mathrm{CH}_{2} \mathrm{~N}_{3}\right.$, $\left.{ }^{3} \mathrm{~J}=4.89 \mathrm{~Hz}\right), 4.50\left(\mathrm{t}, 2 \mathrm{H}, \mathrm{OCH}_{2} \underline{\mathrm{CH}}_{2} \mathrm{~N}_{3},{ }^{3} \mathrm{~J}=5.17 \mathrm{~Hz}\right), 4.72\left(\mathrm{~s}, 2 \mathrm{H}, \mathrm{C}_{2} \mathrm{OH}\right), 7.78(\mathrm{~s}, 1 \mathrm{H}$, 


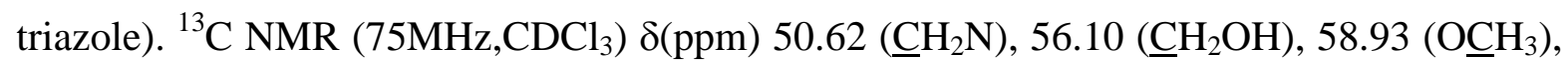
$69.89 \quad\left(\mathrm{OCH}_{2} \mathrm{CH}_{2} \mathrm{~N}\right), \quad 70.43 \quad\left(\underline{\mathrm{CH}}_{2} \mathrm{OCH}_{2} \mathrm{CH}_{2} \mathrm{~N}\right), \quad 70.49 \quad\left(\mathrm{CH}_{3} \mathrm{OCH}_{2} \underline{C H}_{2} \mathrm{O}\right), \quad 70.54$ $\left(\mathrm{CH}_{3} \mathrm{OCH}_{2} \mathrm{CH}_{2} \mathrm{OCH}_{2}\right), 71.82\left(\mathrm{CH}_{3} \mathrm{OCH}_{2}\right), 123.27\left(\underline{\mathrm{CH}}_{\text {triazole }}\right), 147.83\left(\mathrm{C}_{\text {triazole }}\right)$.

\subsubsection{General procedure for the synthesis of monomers (DEGTz) and (TEGTz):}

In a three necked round bottomed flask placed in an ice bath was dissolved $(0.19 \mathrm{~g}, 2.2 \mathrm{mmol})$ acryloyl chloride, $(0.61 \mathrm{~g}, 6 \mathrm{mmol})$ triethylamine in $10 \mathrm{~mL}$ of dry dichloromethane under nitrogen atmosphere. When the mixture becomes homogeneous, (0.4 g, 2mmol) of triazole derivative (3a-b) dissolved in $10 \mathrm{~mL}$ of dry dichloromethane was added. The mixture was heated at $40^{\circ} \mathrm{C}$ for 48 hours. After cooling down to room temperature the organic phase was washed successively with $\mathrm{HCl}$ solution $1 \mathrm{M}$, then with water and finally dried over magnesium sulphate. The solvent was evaporated and the obtained residue was purified by silica gel column chromatography (eluent: $\mathrm{CH}_{2} \mathrm{Cl}_{2} / \mathrm{AcOEt} 4 / 1$ ).

DEGTz: Yield (60\%), $\mathrm{H}^{1} \mathrm{NMR}\left(300 \mathrm{MHz}, \mathrm{CDCl}_{3}\right) \delta(\mathrm{ppm}) 3.30\left(\mathrm{~s}, 3 \mathrm{H}, \mathrm{OC}_{3}\right), 3.45$ (t, $2 \mathrm{H}$, $\left.\mathrm{CH}_{3} \mathrm{OC} \underline{\mathrm{H}}_{2},{ }^{3} \mathrm{~J}=5.01 \mathrm{~Hz}\right), 3.54\left(\mathrm{t}, 2 \mathrm{H}, \mathrm{CH}_{3} \mathrm{OCH}_{2} \mathrm{CH}_{2},{ }^{3} \mathrm{~J}=5.01 \mathrm{~Hz}\right), 3.81\left(\mathrm{t}, 2 \mathrm{H}, \mathrm{OCH}_{2} \mathrm{CH}_{2},{ }^{3} \mathrm{~J}=\right.$ $4.91 \mathrm{~Hz}), 4.50\left(\mathrm{t}, 2 \mathrm{H}, \mathrm{OCH}_{2} \underline{\mathrm{C}}_{2},{ }^{3} \mathrm{~J}=4.91 \mathrm{~Hz}\right), 5.24\left(\mathrm{~s}, 2 \mathrm{H}, \mathrm{C}_{2} \mathrm{O}\right), 5.81\left(\mathrm{dd}, 1 \mathrm{H}, \mathrm{CH}=\mathrm{CH}_{2}\right.$, $\left.{ }^{3} \mathrm{~J}_{\text {cis }}=10.41 \mathrm{~Hz},{ }^{2} \mathrm{~J}=0.76 \mathrm{~Hz}\right), 6.08\left(\mathrm{dd}, 1 \mathrm{H}, \mathrm{CH}=\mathrm{CH}_{2},{ }^{3} \mathrm{~J}_{\text {cis }}=10.41 \mathrm{~Hz},{ }^{3} \mathrm{~J}_{\text {trans }}=18.07 \mathrm{~Hz}\right), 6.37(\mathrm{dd}$, $\left.1 \mathrm{H}, \mathrm{CH}=\underline{\mathrm{CH}}_{2},{ }^{3} \mathrm{~J}_{\text {trans }}=18.07 \mathrm{~Hz},{ }^{2} \mathrm{~J}_{\text {gem }}=0.76 \mathrm{~Hz}\right), 7.79\left(\mathrm{~s}, 1 \mathrm{H}_{\text {triazole }}\right) \cdot{ }^{13} \mathrm{CNMR}\left(75 \mathrm{MHz}, \mathrm{CDCl}_{3}\right)$ $\delta(\mathrm{ppm}) \quad 50.10\left(\underline{\mathrm{CH}}_{2} \mathrm{~N}\right), \quad 57.57\left(\mathrm{O}_{\underline{C}} \mathrm{H}_{3}\right), \quad 58.82\left(\underline{\mathrm{CH}}_{2} \mathrm{OCO}\right), \quad 69.20 \quad\left(\underline{\mathrm{CH}}_{2} \mathrm{CH}_{2} \mathrm{~N}\right), \quad 70.29$ $\left(\mathrm{CH}_{3} \mathrm{OCH}_{2} \underline{\mathrm{CH}}_{2}\right), \quad 71.55\left(\mathrm{CH}_{3} \underline{\mathrm{OCH}}_{2}\right), \quad 124.98\left(\underline{\mathrm{CH}}_{\text {triazole }}\right), \quad 127.89 \quad\left(\mathrm{COCH}=\underline{\mathrm{CH}}_{2}\right), \quad 131.36$ $\left(\mathrm{CO} \underline{\mathrm{C}} \mathrm{H}=\mathrm{CH}_{2}\right), 142.34\left(\underline{\mathrm{C}}_{\text {triazole }}\right), 165.74(\mathrm{C}=\mathrm{O})$.

TEGTz: Yield (62\%), $\mathrm{H}^{1} \mathrm{NMR}\left(300 \mathrm{MHz}, \mathrm{CDCl}_{3}\right) \delta(\mathrm{ppm}) 3.34\left(\mathrm{~s}, 3 \mathrm{H}, \mathrm{OC}_{3}\right), 3.52(\mathrm{t}, 2 \mathrm{H}$, $\left.\mathrm{CH}_{3} \mathrm{OC} \underline{H}_{2},{ }^{3} \mathrm{~J}=4.97 \mathrm{~Hz}\right), 3.59\left(\mathrm{~m}, 6 \mathrm{H}, \mathrm{CH}_{3} \mathrm{OCH}_{2} \underline{\mathrm{CH}}_{2} \mathrm{OCH}_{2} \underline{\mathrm{CH}}_{2} \mathrm{O}\right), 3.85\left(\mathrm{t}, 2 \mathrm{H}, \mathrm{C}_{2} \mathrm{CH}_{2} \mathrm{~N},{ }^{3} \mathrm{~J}=\right.$ $5.17 \mathrm{~Hz}), 4.52\left(\mathrm{t}, 2 \mathrm{H}, \mathrm{OC}_{2} \mathrm{~N},{ }^{3} \mathrm{~J}=5.17 \mathrm{~Hz}\right), 5.27\left(\mathrm{~s}, 2 \mathrm{H}, \mathrm{C}_{2} \mathrm{OCO}\right), 5.82\left(\mathrm{dd}, 1 \mathrm{H}, \mathrm{CH}=\mathrm{C}_{2}\right.$, $\left.{ }^{3} \mathrm{~J}_{\text {cis }}=10.41 \mathrm{~Hz},{ }^{2} \mathrm{~J}_{\text {gem }}=1.45 \mathrm{~Hz}\right), 6.10\left(\mathrm{dd}, 1 \mathrm{H}, \mathrm{CH}=\mathrm{CH}_{2},{ }^{3} \mathrm{~J}_{\mathrm{cis}}=10.41 \mathrm{~Hz},{ }^{3} \mathrm{~J}_{\text {trans }}=17.31 \mathrm{~Hz}\right), 6.40$ $\left(\mathrm{dd}, \quad 1 \mathrm{H}, \quad \mathrm{CH}=\mathrm{CH}_{2},{ }^{3} \mathrm{~J}_{\text {trans }}=17.31 \mathrm{~Hz}, \quad{ }^{2} \mathrm{~J}_{\mathrm{gem}}=1.45 \mathrm{~Hz}\right), \quad 7.83 \quad\left(\mathrm{~s}, \quad 1 \mathrm{H}_{\text {triazole }}\right) . \quad{ }^{13} \mathrm{CNMR}$

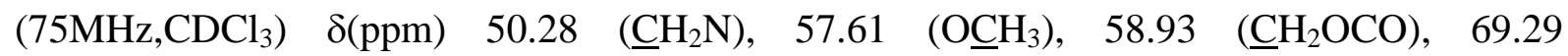
$\left(\mathrm{O}_{2} \mathrm{H}_{2} \mathrm{CH}_{2} \mathrm{~N}\right), 70.39\left(\underline{\mathrm{CH}}_{2} \mathrm{OCH}_{2} \mathrm{CH}_{2} \mathrm{~N}\right), 70.42\left(\mathrm{CH}_{3} \mathrm{OCH}_{2} \underline{\mathrm{CH}_{2}}\right), 70.48\left(\mathrm{CH}_{3} \mathrm{OCH}_{2} \mathrm{CH}_{2} \mathrm{OCH}_{2}\right)$, $71.83\left(\mathrm{CH}_{3} \mathrm{OCH}_{2}\right), 125.13\left(\underline{\mathrm{CH}}_{\text {triazole }}\right), 128.00\left(\mathrm{COCH}=\underline{\mathrm{CH}_{2}}\right), 131.42\left(\mathrm{CO} \underline{\mathrm{CH}}=\mathrm{CH}_{2}\right), 142.4$ $\left(\mathrm{C}_{\text {triazole }}\right), 165.92(\underline{\mathrm{C}}=\mathrm{O})$. 


\subsection{Preparation of latexes}

Emulsion polymerizations were carried out in a glass reactor equipped with a glass paddle agitator and a condenser. The temperature was controlled at $70^{\circ} \mathrm{C}$ and the stirring rotation was kept constant (300 rpm).

\subsubsection{Batch polymerization}

The recipes of the different prepared latexes are reported in table 1. Deionized water was introduced in a reactor and the temperature was raised to $70^{\circ} \mathrm{C}$. Styrene (for SDZ1, SDZ2, SDZ3, STZ1, STZ2 latexes) or styrene-d8 (for SdDZ, SdTZ latexes) and monomer DEGTz or TEGTz, were then charged and the stirring rate was maintained until temperature stabilization. Polymerization was initiated by introducing KPS and was allowed to proceed for 21 hours.

Polystyrene and Perdeuterated polystyrene homopolymers were prepared according to the same procedure without addition of acrylic monomers DEGTz and TEGTz.

Polymerization conversions were determined gravimetrically and by NMR analysis as reported in the next section. For kinetic studies, sampling of the reaction mixture at various time intervals was performed to control the polymerization conversion and the particle sizes.

Table 1. Latex recipes for batch process

\begin{tabular}{lcccccccc}
\hline Reagents & PS & SDZ1 & SDZ2 & SDZ3 & STZ1 & STZ2 & SdDZ & SdTz \\
\hline Styrene (g) & 3 & 3 & 3 & 3 & 3 & 3 & - & - \\
Styrene-d8 (g) & - & - & - & - & - & - & 3 & 3 \\
DEGTz (g) &.- & 0.1 & 0.2 & 0.3 & - & - & 0.2 & - \\
TEGTz (g) & - & - & - & - & 0.1 & 0.2 & - & 0.2 \\
KPS (g) & 0.1 & 0.1 & 0.1 & 0.1 & 0.1 & 0.1 & 0.1 & 0.1 \\
Water (g) & 50 & 50 & 50 & 50 & 50 & 50 & 50 & 50 \\
\hline
\end{tabular}

\subsubsection{Shot growth polymerization (latexes SSdDZ and SSdTZ)}

In $80 \mathrm{~mL}$ a glass reactor, was introduced of water then the temperature was raised to $70^{\circ} \mathrm{C}$ and $3 \mathrm{~g}$ of styrene- $\mathrm{d}^{8}$ were charged. After thermal stabilization, $0.1 \mathrm{~g}$ of KPS was added. The stirring was maintained during $21 \mathrm{~h}$ at a stirring rate of $300 \mathrm{rpm}$. Afterward, acrylic monomer 
(DEGTz or TEGTz) and $0.6 \mathrm{~g}$ of styrene-d8 were charged and the reaction mixture was stirred during $2 \mathrm{~h}$. Finally, another quantity of KPS was added and the polymerization reaction was allowed to proceed for additional $21 \mathrm{~h}$.

Table 2. Latex recipes for shot-growth process

\begin{tabular}{lccc}
\hline Reagents & PSd & SSdDZ & SSdTZ \\
\hline Styrene-d8 (g) & $3+0.6$ & $3+0.6$ & $3+0.6$ \\
DEGTz (g) &.- & 0.2 & - \\
TEGTz (g) & - & - & 0.2 \\
KPS (g) & 0.2 & 0.2 & 0.2 \\
Water (g) & 50 & 50 & 50 \\
\hline
\end{tabular}

\subsection{Characterization of polymer particles}

The final polymer content ( $\mathrm{g} / \mathrm{g}$ of latex) was determined via gravimetric method from which the overall conversion was deduced. The various latexes obtained after solvent evaporation were analyzed by ${ }^{1} \mathrm{H}$ NMR in $\mathrm{CDCl}_{3}$ from which the polymerization conversions and the polymer compositions were deduced.

Particle size and size distribution measurements of the prepared latex particles were carried out by dynamic light scattering technique (DLS) using Zetasizer (NANO ZS, Malvern instruments). A small drop of sample was dispersed in $1 \mathrm{ml}$ of deionized water. The measurement was repeated for three times. Zeta potentials of particles were determined as function of $\mathrm{pH}$ values using the Malvern Zetasizer via electrophoretic mobility measurements. Different $\mathrm{pH}$ solutions were prepared using $1 \mathrm{mM} \mathrm{NaCl}$ solution and the $\mathrm{pH}$ values were adjusted by $1 \mathrm{mM} \mathrm{NaOH}$ or $1 \mathrm{mM} \mathrm{HCl}$ solution using a $\mathrm{pH}$-meter. The samples were diluted in the corresponding solution before measuring the electrophoretic mobility.

The morphology and sizes were also examined by transmission electron microscope TEM (Phillips CM120, CMEABG, University of Claude Bernard Lyon 1). A highly diluted aqueous latex dispersion was deposited a carbon-coated copper grid then dried at room temperature overnight before TEM imaging. The dried samples were imaged under 120 $\mathrm{kV}$ acceleration voltages. 


\section{Results and discussion}

\subsection{Synthesis}

1,2,3-triazole-based acrylic monomers containing diethylene or triethylene glycol monomethyl ether groups, DEGTz and TEGTz respectively were prepared through 4 steps procedure as represented in scheme 1.

The synthetic strategy involves the reaction of diethylene glycol methyl ether or triethylene glycol methyl ether with p-toluenesulfonyl chloride followed by the conversion of the obtained tosyl compounds (1a-b) to azide derivatives (2a-b) in the presence of sodium azide in reflux of dimethylformamide. The addition of propagylalcohol to compounds (2a-b) in the condition of copper-catalyzed 1,3-dipolar cycloaddition reaction affords the 1,2,3- triazole derivatives (3a-b). In these reaction conditions, only the 1,4-regioisomers were obtained as confirmed by ${ }^{1} \mathrm{H}$ and ${ }^{13} \mathrm{C}$ NMR analyses. Subsequent reaction with acryloyl chloride leads to the corresponding acrylic monomers DEGTz and TEGTz with good yield. The presence in ${ }^{1} \mathrm{H}$ NMR spectra of the signals related to the acrylic protons at 5.81-6.38 ppm $\left(=\mathrm{CH}_{2}\right)$ and $6.09 \mathrm{ppm}(\mathrm{CH}=), \mathrm{H}_{5}$-triazole $(7.79-7.83 \mathrm{ppm})$ and that of the terminal methoxy group (3.34$3.45 \mathrm{ppm}$ ) indicates that the monomers were successfully synthesized.
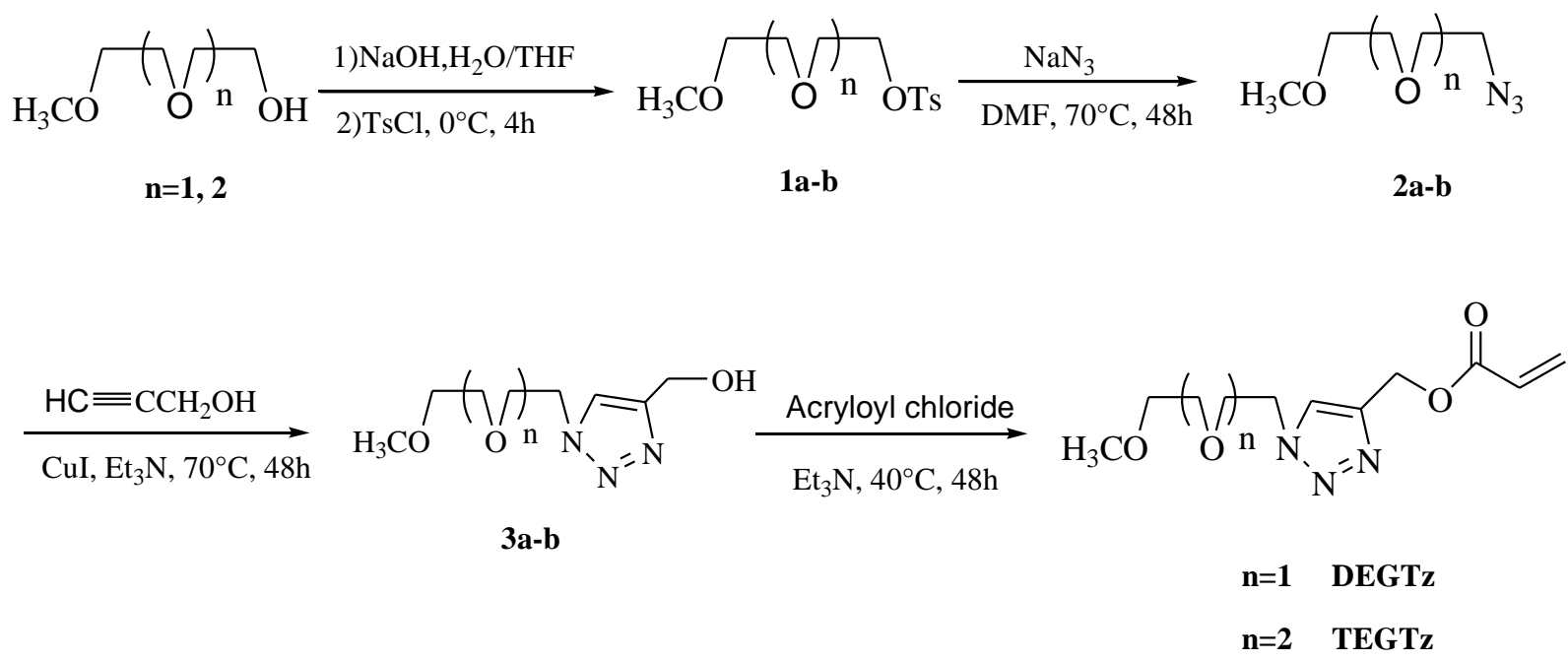

Scheme 1.Synthetic procedure of monomers DEGTz and TEGTz

\subsection{Styrene polymerization}

Acrylic monomers DEGTz and TEGTz were compared for their efficiency in free-surfactant emulsion polymerization with styrene by using batch polymerization procedure. 
Firstly, polymerization reactions have been carried out at 94/6 styrene/monomer weight ratio with KPS as initiator (latexes SDZ2 and STZ2 respectively). The analysis of the sera by ${ }^{1} \mathrm{H}$ NMR, showed that almost total polymerization conversions have been reached for these systems instead of $86 \%$ for styrene homopolymerization (table 3). Similar increase of polymerization conversion has been previously reported for emulsifier-free copolymerization of styrene with hydrophilic reactive monomers and was attributed to the influence of such monomers on the early step of nucleation where large number of precursor particles are formed which rapidly suffer a limited coagulation period providing mature particles [18-20].

DLS analysis showed a significant decrease in mean particle diameters and polydispersity index for both investigated latexes in comparison with polystyrene latex (PS). This result suggests that these monomers act as efficient active-surface agents in emulsion polymerization process.

This feature was particularly noticeable for acrylic based triazole monomer DEGTz bearing diethyleneglycol methylether chain where rather monodisperse particles (PDI $=0.069)$ with a mean diameter of $266 \mathrm{~nm}$ have been obtained whereas TEGTz monomer conducted to larger particles $(393 \mathrm{~nm})$ with slightly higher polydispersity index.

The higher efficiency of DEGTz monomer in reducing particle size in comparison to TEGTz analogous may be explained by the difference of the chemical structure of the two investigated surfactants. In TEGTz, the hydrophilic ethyleneglycol chain is longer than in DEGTz. The longer ethyleneglycol chain, the more it will be extending into water phase to the detriment of the hydrophobic part of the monomer that anchors into monomer droplets and latexes. Thus DEGTz with the less hydrophilic chain will act as a better stabilizer for emulsion polymerization by means of adsorption phenomena and allows the formation of smaller particle sizes compared with the system with TEGTz. It should also generate higher number of precipitating oligo radicals during nucleation stage and prevents of particles from flocculation in the growth step. For TEGTz monomer, homopolymer formation will be more favored as confirmed by NMR analysis of polymerization recipes reported in the next section (see also table 3).

Transmission electron microscopy was used to examine the morphology of SDZ2 and STZ2 particles (Figure 1B and 1E). The investigated latex particles exhibit homogeneous spherical shape. Similarly to DLS analysis, a slightly more polydisperse particles with polyelectrolytes formation were evidenced for STZ2 latex. It is however worth mentioning that particle size obtained from TEM analysis were lower than obtained from light scattering measurements 
reported in table 3 probably due to the shrinking of the latex particles under the electron beam. Furthermore, since TEM analysis described the size in the dried state of the sample, whereas DLS measured the size in the hydrated state, the size measured by DLS is rather a hydrodynamic diameter and had a larger value.

Table 3. Results of surfactant-free batch polymerization of styrene with DEGTz and TEGTz

\begin{tabular}{cccccccc}
\hline Latex & $\begin{array}{c}\text { Triazole } \\
\text { Monomer }\end{array}$ & $\begin{array}{c}\text { Particle } \\
\text { Size } \\
(\mathrm{nm}) \\
\text { DLS(TEM) }\end{array}$ & PDI & $\begin{array}{c}\text { Zeta } \\
\text { Potential } \\
(\mathbf{m v})\end{array}$ & $\begin{array}{c}\text { Overall } \\
\text { Conversion } \\
(\%)\end{array}$ & $\begin{array}{c}\text { Copolymer } / \\
\text { Homopolymer } \\
\text { ratio (mol \%) }\end{array}$ & $\begin{array}{c}\text { Triazolic } \\
\text { monomer on } \\
\text { particles (mol \%) }\end{array}$ \\
\hline PS & - & 777 & 0.258 & -47.3 & 83 & - & - \\
SDZ1 & DEGTz & $577(285)$ & 0.248 & -56.5 & 99 & $65 / 35$ & 19 \\
SDZ2 & DEGTz & $266(203)$ & 0.069 & -55.5 & 99 & $67 / 33$ & 27 \\
SDZ3 & DEGTz & $495(345)$ & 0.129 & -43.2 & 99 & $61 / 39$ & 28 \\
STZ1 & TEGTz & $643(514)$ & 0.203 & -57.5 & 97 & $63 / 37$ & 19 \\
STZ2 & TEGTz & $393(293)$ & 0.137 & -52.1 & 98 & $52 / 48$ & 28 \\
\hline
\end{tabular}
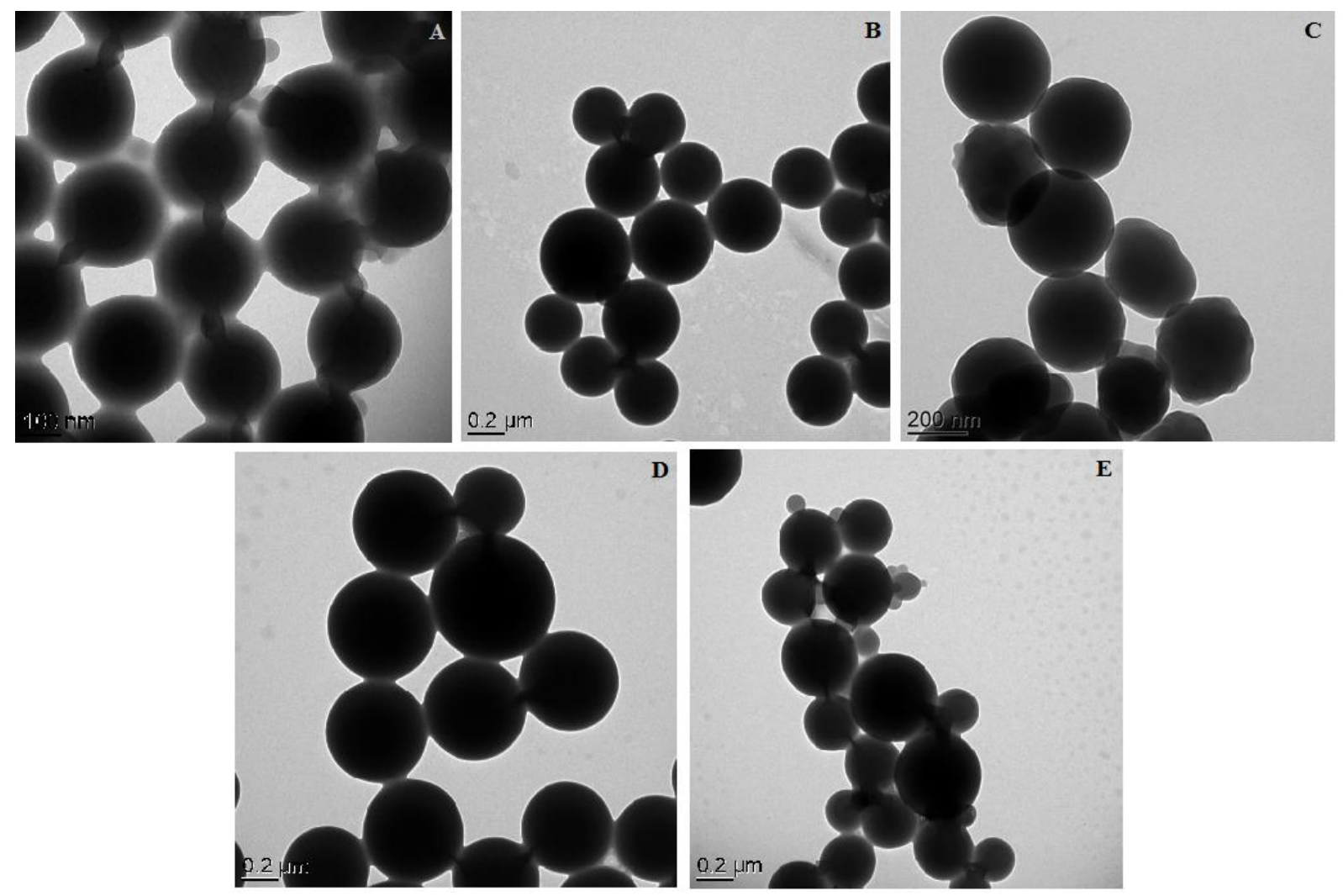

Fig 1. TEM micrographs A) SDZ1, B) SDZ2, C) SDZ3, D) STZ1, E) STZ2 


\section{Kinetic}

Figure 2 presents the particle size evolution of the latex particles SDZ2 and STZ2 calculated by DLS as a function of polymerization time. The emulsion polymerization reactions of acrylic triazole monomers DEGTz and TEGTz with styrene have been carried out at in the same previously used conditions, i.e. styrene/monomer weight ratio (94/6), 6.6\% solid content and 3 wt.\% of KPS. Polystyrene homopolymer was prepared under the same conditions for comparison.

For all investigated systems, gradual increase of particle size during the first $240 \mathrm{~min}$ polymerization reaction was observed followed by a stabilization at 777, 265 and $392 \mathrm{~nm}$ for PS, SDZ2 and STZ2 latexes respectively.

Interestingly, SDZ2 and STZ2 latexes exhibit much lower particle sizes than polystyrene particles during the whole investigated time reaction. The particle size distribution remained narrow through the process for the both systems in the range of $0.014-0.222$ and $0.097-0.184$ for SDZ2 and STZ2, respectively with a limited amount of aggregated particles (coagulum).

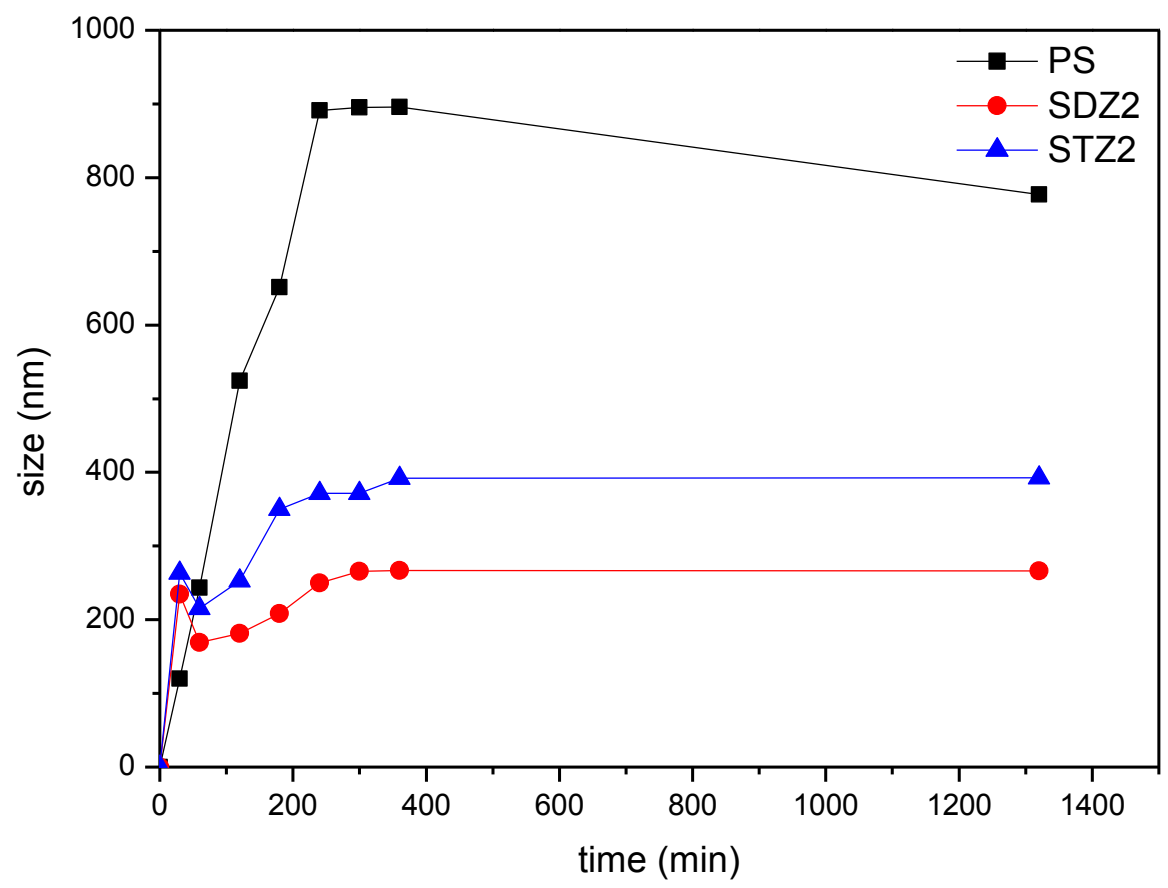

Fig 2. Evolution of particle size with polymerization time for PS, SDZ2 and STZ2 latexes. 


\section{Effect of monomer concentration}

The polymerization of styrene was also conducted at various concentrations of triazolic monomers (3, 6 and 9 wt.\% for DEGTz and 3 and 6 wt.\% for TEGTz in comparison to styrene) with constant concentration of KPS. From table 3, we can see that when the concentration of DEGTz or TEGTz monomer increases from 3 to 6 wt.\%, there is a significant decrease in mean particle diameters (i.e. 577 to $266 \mathrm{~nm}$ and 643 to $393 \mathrm{~nm}$ for DEGTz and TEGTz respectively). Further increase on DEGTz concentration leads to larger particles (495 nm); which is assumed to be because of the enhanced particle coagulation. This behavior can be related to the increase of water-soluble oligomer contents and/or the reduction of the precipitation of oligo radicals during the nucleation stage.

Figure 1 shows TEM images of these investigated particles. By increasing triazolic monomer content, the particle morphology slightly deviated from spherical shape to irregular and more polydisperse shape with some occlusions at particle surfaces.

Such particle morphology has been already reported for emulsifier-free copolymerization of styrene with hydrophilic monomers as NIPAM [18] and acryloylpiperidine [21] and can be explained by a two-step mechanism as follows: at the beginning of polymerization process, triazolic monomer will rapidly reacts due to its favorable partitioning in aqueous phase to form polymer chains that precipitate rapidly onto unstable nuclei and coagulate to produce larger particles. When almost the major quantity of triazolic monomer polymerized, styrene starts to react by the diffusion of the monomer from the droplets and the subsequent swelling of the polytriazolic-rich particles. Due to the poor compatibility between the already formed polytriazolic polymers and styrene-rich chains, a phase separation occurs leading to the formation of occlusion at the surface of particles. As the polymerization proceeds, the polystyrene-rich phase will be predominant, expelling the most of polytriazole at the particle surface as small asperities.

\section{Zeta potential}

Zeta potential is considered as an important parameter that reflects the charge of particle surfaces and the intensity of repulsive forces among particles affect the stability of dispersion. In this study, zeta potential was measured for polystyrene latexes at different $\mathrm{pH}$ ranging from 3 to 11 . The obtained zeta potential data are plotted in figure 3. One can see that zeta potential values of all investigated particles are negative ranging from -23 to $-73 \mathrm{mv}$ over the whole range of measured $\mathrm{pH}$ probably due the presence of sulfate functions of potassium 
persulfate initiator (KPS) on polystyrene particle surface. Any isoelectric point was observed for these latexes.

The evolution of zeta potentials exhibits the same Gaussian profile as a function of $\mathrm{pH}$ with a maximum $\zeta$ value for $\mathrm{pH}$ in between 8 and 9. All $\zeta$ values are found to increase with increasing DEGTZ triazolic monomer concentration (latexes SDZ1, SDZ2 and SDZ3) whereas no significant changes were observed for latex prepared with TEGTz (STZ1 and STZ2). It seems however that for similar initial monomer content, the latter latexes present slightly higher zeta potential values and particularly for $\mathrm{pH}>6$ which can be related to the presence of neutral adsorbed polytriazole polymers.

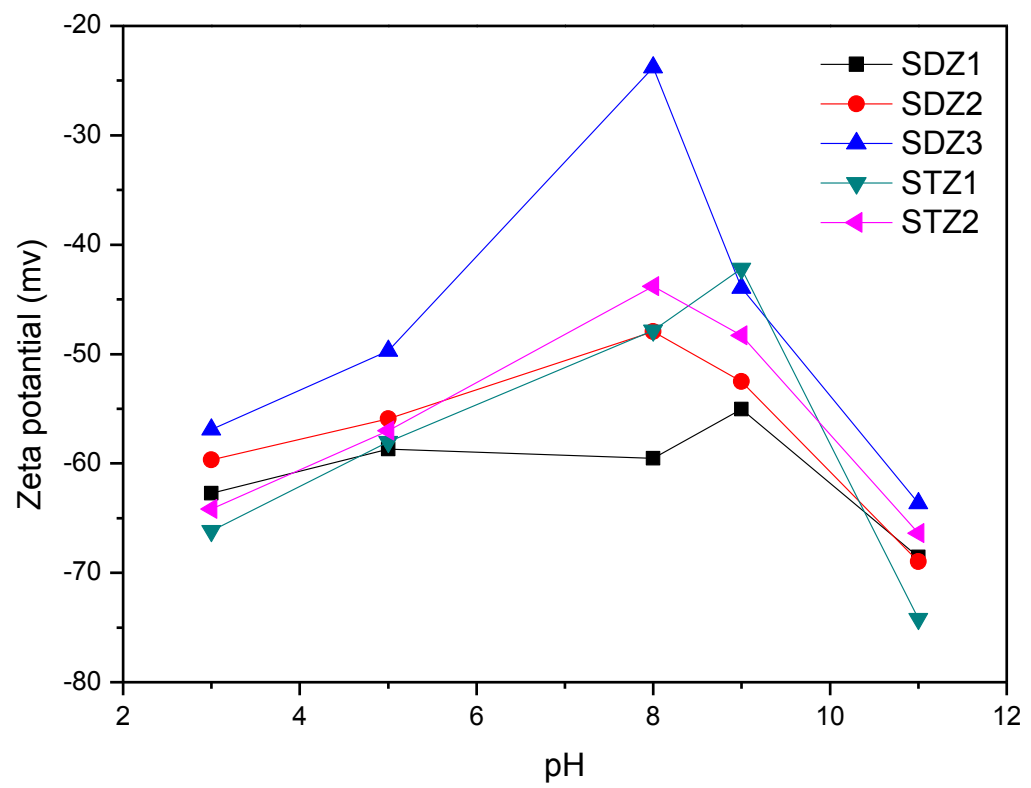

Fig 3. Zeta potential of latexes prepared by batch polymerization of styrene with DEGTz and TEGTz as function of $\mathrm{pH}$

\section{NMR study}

${ }^{1} \mathrm{H}$ NMR was used to examine the composition of polymer particles. By using $\mathrm{D}_{2} \mathrm{O}$ as solvent, only the signals related to triazole-based monomers are observed since $\mathrm{D}_{2} \mathrm{O}$ is non-solvent of the hydrophobic polystyrene core. In $\mathrm{CDCl}_{3}$, both shell and core chains were noticed that allows the determination of the composition of the polymers. Comparative NMR spectra of DEGTz monomer and corresponding homopolymer and polystyrene copolymer latex SDZ1 are given as an example in figure 4. The presence of resonance peaks belonging to triazolic monomer and styrene moieties is clearly evident in copolymer spectra. Moreover, we noticed the coexistence of two signals at 7.41 and 7.39 ppm that was assigned to H5-triazolic signal of 
polytriazole homopolymer and copolymer respectively. This was confirmed by two ways: a) by comparing with NMR spectra of polytriazole homopolymer prepared in the same condition, b) NMR spectra of this latex carried out in $\mathrm{D}_{2} \mathrm{O}$ instead of $\mathrm{CDCl}_{3}$ shows only one H5-triazolic signal of the water soluble pegylated triazole homopolymer (figure 4c).

The integral area of these two protons was used to calculate the mole ratio of copolymer/homopolymer in investigated latexes. The content of acrylic DEGTz and TEGTz moiety in copolymer particles was also estimated from ${ }^{1} \mathrm{H}$ NMR spectra of latexes by comparing the signal of styrene moiety $(7.11$ or $6.60 \mathrm{ppm})$ with that of H5-triazole of copolymer. The obtained results are collected in table 3.

It was found that the initial feed composition used to prepare polystyrene particles has significant effect on the composition of the final copolymer particles. The increasing of the initial concentration of triazolic monomer leads to higher incorporation of triazole monomer in latex particles. However, it is noticed in the same time that the formation of polytriazole water soluble oligomers was more favored particularly for monomer bearing the longer pegylated chain (TEGTz). This result is in good agreement with TEM and DLS results discussed previously.

All these results give more insight concerning the polymerization mechanism of triazole monomer under these heterogeneous conditions. In conventional emulsion polymer systems using water-insoluble monomer such as styrene, the primary reaction locus is inside the polymer particles, and aqueous-phase polymerization is usually considered to be negligible. Since pegylated triazolic acrylic monomers are "partially" soluble in water, they will probably be partitioned between both the organic and aqueous phases. We can expect that the primary reaction locus in the triazole-styrene system shifts from the particles to the aqueous phase after the hydrophobic styrene monomer has been consumed. Thereby, oligomeric radicals can be formed in the aqueous phase and will play an important role in particle nucleation and stabilization. We can expect that for DEGTz and TEGTz monomers, the water-soluble oligomers will grow in both the aqueous phase and the organic phase and will impact substantially the composition of final polymers. In aqueous phase, more triazolic sequence units in the oligomer chains will be formed owing to the higher triazolic acrylic monomer concentration there. This feature will be more pronounced for monomer TEGTz containing longer hydrophilic chain. Similar behavior was reported by Shoaf and Poehlein [22-23] for seeded emulsion copolymerization of styrene with hydrophilic acrylic acids systems. 

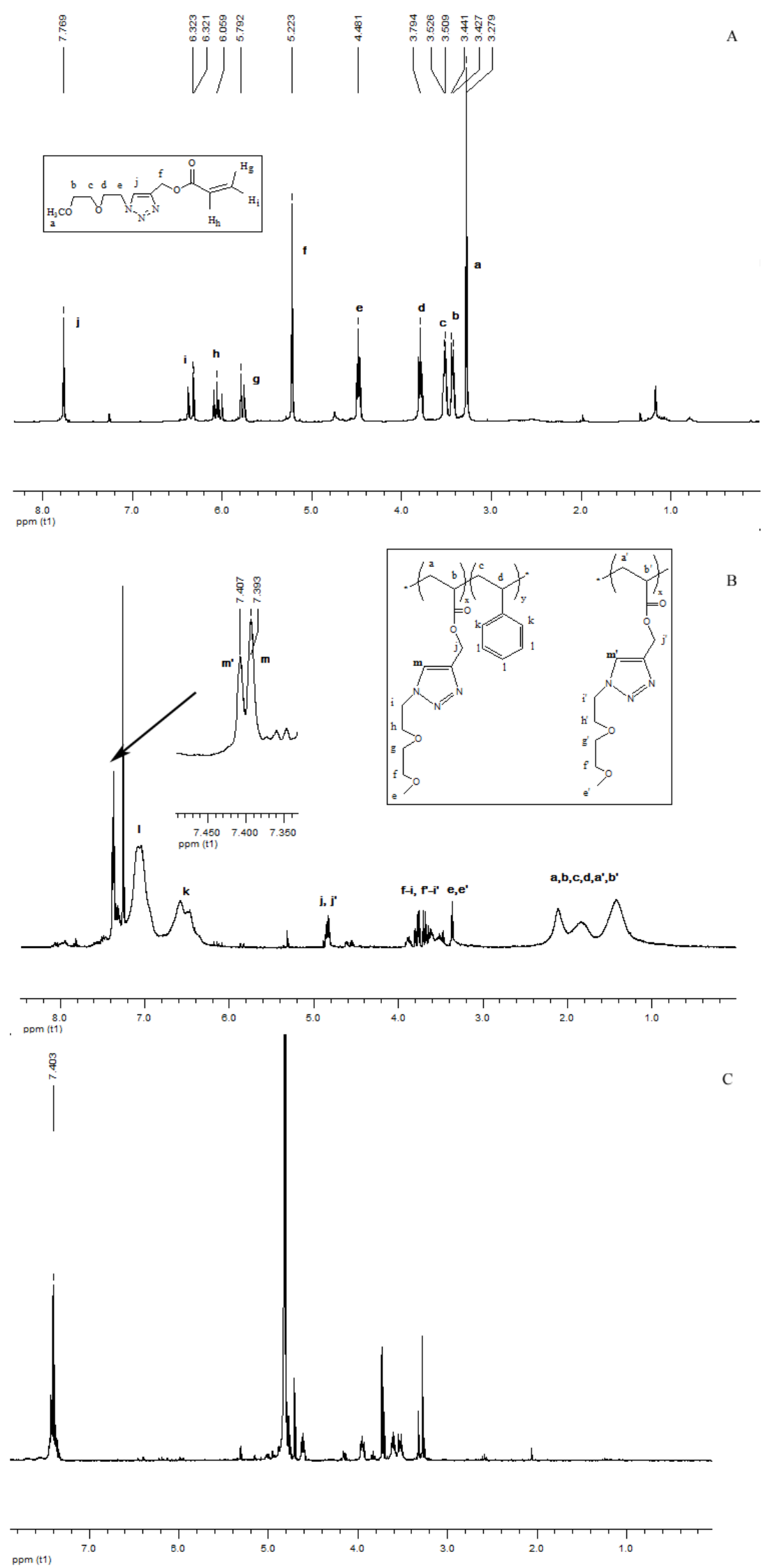

Fig 4. ${ }^{1} \mathrm{H}-\mathrm{NMR}$ spectra of a) DEGTz, b) $\mathrm{SDZ} 1$ in $\mathrm{CDCl}_{3}$ and c) in $\mathrm{D}_{2} \mathrm{O}$ (homopolymer) 


\subsection{Perdeuterated styrene polymerization}

The polymerization of DEGTz or TEGTz monomers with perdeuterated styrene was carried out under free-surfactant polymerization condition at $70^{\circ} \mathrm{C}$ and $6 \%$ solid content by using KPS as initiator.

Two series of experiments have been considered. First, batch copolymerization of styrene- $\mathrm{d}^{8}$ with triazolic monomers DEGTz and TEGTz was conducted; the related latexes are named SdDZ and SdTZ, respectively (table 4). The second series of experiments consists on shotgrowth polymerization. In this case, the corresponding latexes are noted SSdDZ and SSdTZ respectively.

One can see in table 4 that in batch condition, polymerization of perdeuterated styrene proceeds with good yield to afford monodisperse latex particles PSd in the range size of 662 $\mathrm{nm}$. Copolymerization recipes SdDZ and SdTZ showed a strong decrease of the particle sizes confirming that the triazolic monomers act as efficient surface-active agents in heterogeneous polymerization by providing stability to the particles. The particle sizes achieved by DEGTz and TEGTz (370 and $660 \mathrm{~nm}$ for SdDZ and SdTZ latexes respectively) were however larger and slightly more polydisperse than those obtained for previously discussed polystyrene based latexes SDZ2 and STZ2 (266 and $393 \mathrm{~nm}$ respectively).

The morphology and particle size distribution of these systems was also investigated by TEM analysis. Monodisperse spherical particles with a smooth surface have been obtained for perdeuterated polystyrene particles PSd (figure 5a). By copolymerization with triazolic monomers, the particle morphology slightly deviated from spherical shape to irregular raspberry-like shape (Figure 5b-d). The deviation is more important for SdTZ particles where many bulges are present on the particle surfaces. This behavior is supported by the higher polydispersity index value of 0.228 calculated by DLS analysis for these particles. The particle size determined by TEM analysis was, as observed previously, smaller than those calculated by DLS in the range of 327 and $544 \mathrm{~nm}$ for SDZ2 and STZ2, respectively.

The findings of this study proved that the polymerization process and particles morphology are significantly affected by styrene deuterium substitution. Previous studies have reported the influence of the isotopic effect of deuterium substitution on the rate of free-radical polymerization for some deuterated monomers. The rate of propagation $\mathrm{Rp}$ was found to be dependent on the position of the deuterium and was in most cases higher for the deuterated monomer than for the H-monomer. In the case of perdeuterated styrene, Clouet and 
Chaffanjon [24] have shown that the deuterium substitution affects not only the propagation step of the polymerization of styrene-d8 but also the termination step. The activation energy for termination step of styrene-d8 was found to be 1.5 times higher than for styrene and an increase in termination reaction by combination was obtained for the former monomer was reported. This feature can explain in our case, the lower conversion yields and the more heterogeneous particle surface observed for polymers prepared from perdeuterated styrene in comparison with styrene based analogous (table 3). ${ }^{1} \mathrm{H}$ NMR study carried out for perdeuterated polystyrene recipes (figure 6 and b) showed lower monomer conversion for perdeuterated polystyrene particles in comparison with polystyrene analogous and higher amounts of water-soluble polymers. We can expect a higher demixing of the small polystyrene-rich domains during polymerization leading to the formation of the occlusions at particle surfaces as observed by TEM analysis.

In a second time, polymerization experiments were performed under shot-growth conditions in the aim to have a better control of the amount of triazole based monomer copolymerized at the surface of polystyrene particles. The basis of the shot growth technique is to polymerize the main monomer, i.e. styrene- $\mathrm{d}^{8}$, by the usual surfactant-free emulsion polymerization process until the seed latex reaches a fairly high conversion $(>60 \%)$ then the second monomer (DEGTz or TEGTz) is added and the reaction is allowed to proceed to completion.

Results as regards to particle size and distribution are reported in table 4 (latexes SSdDZ and SSdTZ). Moderate conversion yields were obtained for both investigated acrylic monomers. Dynamic light scattering analysis showed particles with large sizes ranging from $568 \mathrm{~nm}$ and $834 \mathrm{~nm}$ with broad size distribution. Nevertheless, TEM micrographs of these latexes reveal more homogeneous spherical particles with smaller particles size in the range of $314 \mathrm{~nm}$ and $538 \mathrm{~nm}$ for SSdDZ and SSdTZ respectively but with a high tendency for aggregation. It is worth mentioning that these values are slightly lower than those obtained by batch polymerization. 
Table 4. Results of surfactant-free polymerization of perdeuterated styrene with DEGTz and TEGTz in batch and shot-growth conditions (Styrene $\mathrm{d}^{8}(3 \mathrm{~g})+$ triazolic Monomer $(0.2 \mathrm{~g})$ )

\begin{tabular}{|c|c|c|c|c|c|c|}
\hline \multirow[t]{2}{*}{ Latex } & \multirow{2}{*}{$\begin{array}{l}\text { Triazolic } \\
\text { Monomer }\end{array}$} & \multirow{2}{*}{$\begin{array}{l}\text { Particle } \\
\text { Size } \\
(\mathrm{nm}) \\
\text { DLS(TEM) }\end{array}$} & \multirow[t]{2}{*}{ PDI } & \multicolumn{2}{|c|}{$\begin{array}{c}\text { Overall } \\
\text { Conversion }(\%) \\
\end{array}$} & \multirow{2}{*}{$\begin{array}{l}\text { Copolymer / } \\
\text { Homopolymer } \\
\text { ratio }(\mathrm{mol} \%)\end{array}$} \\
\hline & & & & $\begin{array}{c}\text { From } \\
\text { Gravimetry }\end{array}$ & $\begin{array}{c}\text { From } \\
{ }^{1} \mathrm{H} \\
\text { NMR }\end{array}$ & \\
\hline PSd & - & 662 & 0.214 & 72 & - & \\
\hline $\mathrm{SdDZ}$ & DEGTz & $370(327)$ & 0.012 & 61 & 65 & $23 / 77$ \\
\hline SdTZ & TEGTz & $660(544)$ & 0.228 & 66.8 & 71.6 & $19 / 81$ \\
\hline SSdDZ & DEGTz & $568(314)$ & 0.349 & - & 62.1 & $6 / 94$ \\
\hline SSdTZ & TEGTz & $834(538)$ & 0.187 & - & 62.7 & $2 / 98$ \\
\hline
\end{tabular}



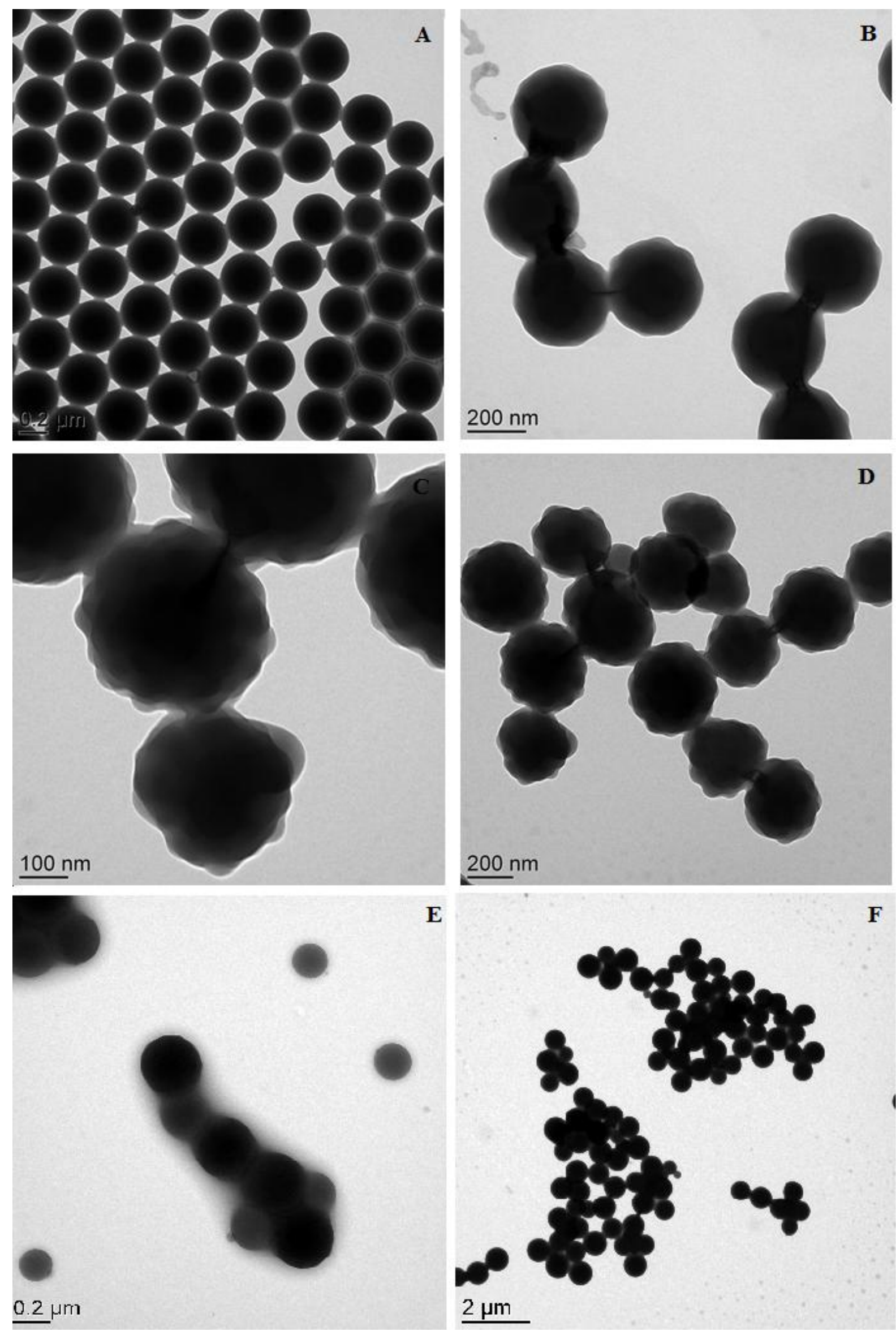

$0.2 \mu \mathrm{m}$

Fig 5. TEM micrographs A) PSd, B) SdDZ, C), D) SdTZ, E) SSdDZ, F) SSdTZ 
By comparing NMR spectra of latexes prepared by batch and shot-growth conditions for both investigated triazolic monomer (figure 6), we noticed that this latter mode of polymerization promotes the formation water-soluble polymers at the detriment of the formation of copolymers (table 4). The smoother particle surfaces observed by TEM analysis for these latexes can be the consequence of a) the formation of less polystyrene-rich domains during polymerization process and b) a better capture of the core particles for polymer from the aqueous phase due to the monomer shell actively polymerizing at the core particle surface. This shell becoming entwined in the polymer matrix, and unable to transfer back out of the particle. The core particles will contain also some residual monomer that will act as plasticizer. The less rigid, plasticized core particles will probably favor more regular spherical shape [25].

a)

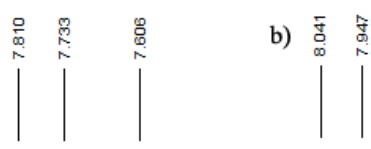

c)

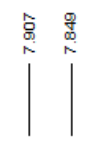

d)

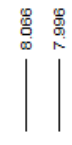

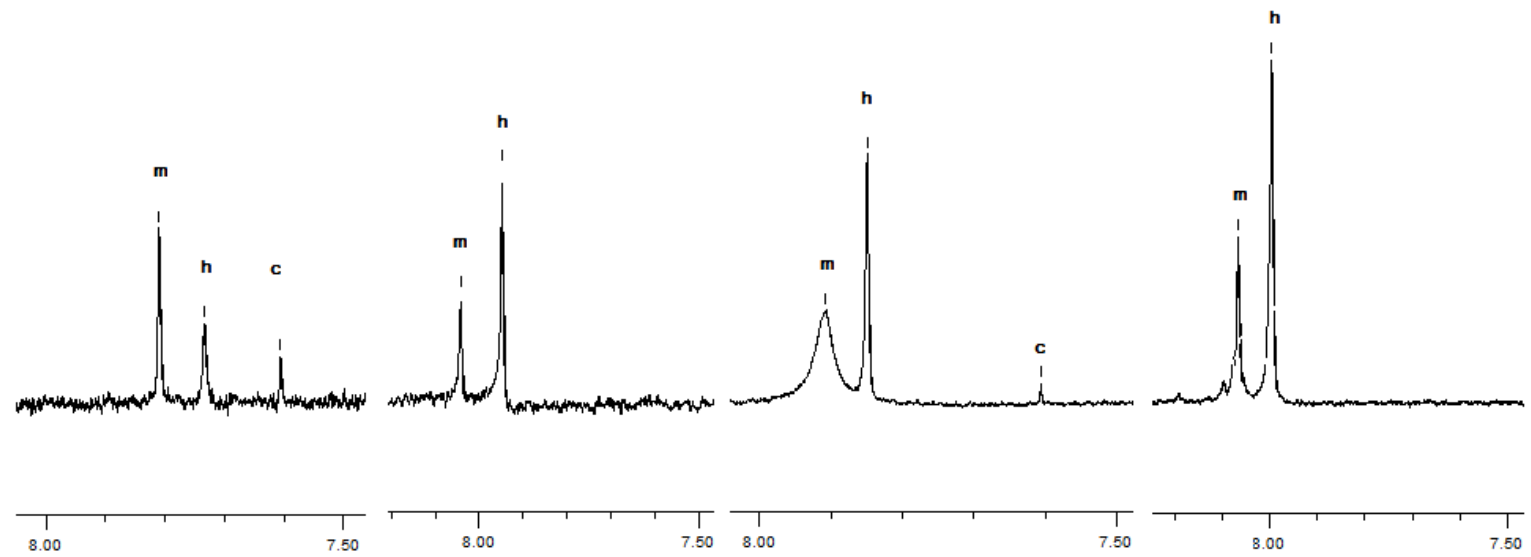

Fig 6. ${ }^{1} \mathrm{H}$ NMR spectra of $\mathrm{SdDZ}$ in a) $\mathrm{CDCl}_{3}$, b) $\mathrm{D}_{2} \mathrm{O}$; $\mathrm{SSdDZ}$ in c) $\mathrm{CDCl}_{3}$, d) $\mathrm{D}_{2} \mathrm{O}$

In this study, zeta potential was also measured for all samples at different $\mathrm{pH}$ i.e. $\mathrm{pH} \mathrm{3,5,8,9}$ and 11 . The resulting values are plotted according to $\mathrm{pH}$ in figure 7.

One can see that polymers prepared by shot-growth polymerization technic exhibit higher $\zeta$ values particularly in acidic media in comparison to polystyrene particles and corresponding batch polymers. This can be related to the high concentration of water-soluble polytriazolic 
species as showed previously in NMR study. One can expect that the triazole ring can undergo protonation reaction at acid $\mathrm{pH}$ values leading to positively charged triazolium groups and thus an increase of zeta potential values.

TEGTz based latex (SdTZ or SSdTZ) exhibit higher zeta potential values in comparison with DEGTz based particles (SdDZ or SSdDZ). This behavior was more pronounced in the case of polymers prepared in shot-growth conditions

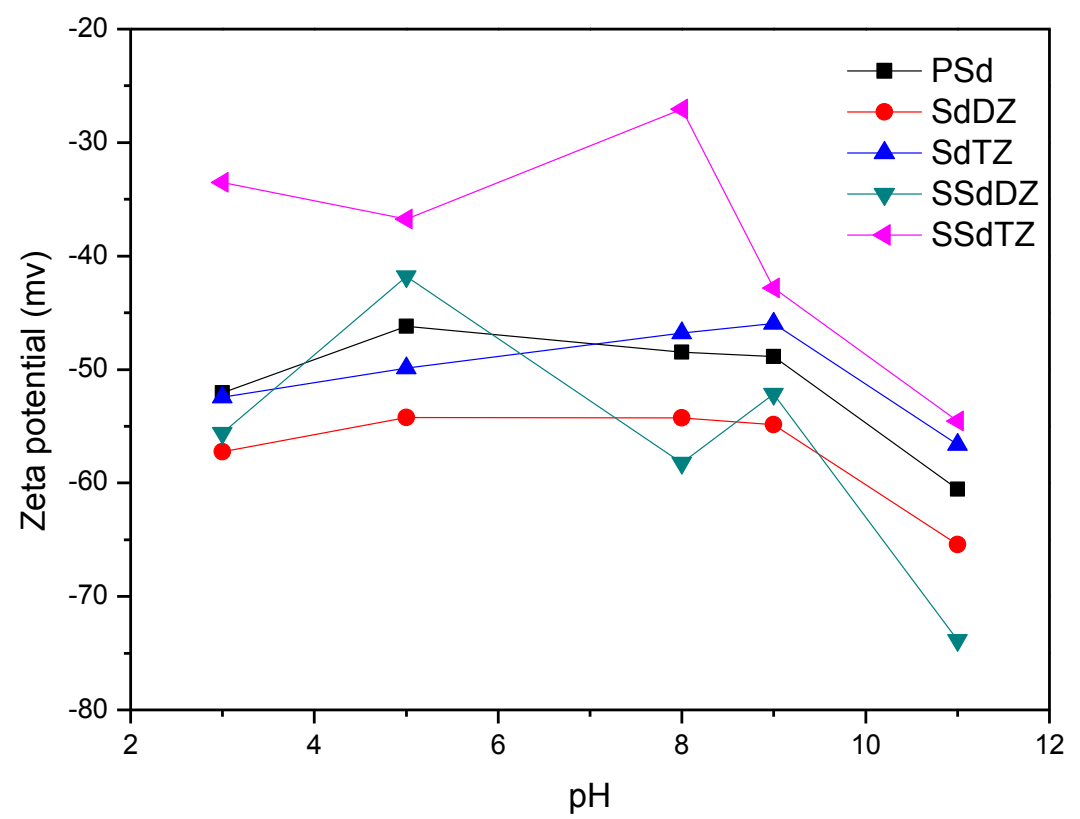

Fig 7. Zeta potantiel of perdeuterated polystyrene particles functionalized with DEGTz and TEGTz monomers as a function of $\mathrm{pH}$.

\section{Conclusion}

Two pegylated triazolic monomers were synthesized and used in emulsifier-free copolymerization of styrene by batch process for producing latex particles with covalently attached triazolic residues. Both investigated monomers strongly affected emulsion copolymerization rate and final particle size and surface charge density. DEGTz monomer bearing the shorter hydrophilic chain allowed the formation monodisperse particles with the smaller particle size. Particle size and surface charge density of the prepared particles were found to be dependent on monomer concentration. Owing to partially hydrophilic character of the monomers, the concomitant formation of polytriazolic homopolymer was evidenced by ${ }^{1} \mathrm{H}$ NMR study particularly for TEGTz monomer. In addition to ionic groups originated from 
initiator, these polymers will probably participate on latex stability via electrostatic stabilization.

These monomers have been then successfully engaged on emulsion polymerization with styrene-d 8 by batch or shot growth processes. The use of deuterated styrene affects substantially the polymerization process and particle morphology and size.

Dealing with short-growth process conducts to higher formation of homopolytriazole particles that was evidenced by NMR analysis and through the electrophoretic mobility behavior of the triazolic functionalized latexes.

Due to the well-known chelating properties of 1,2,3-triazole heterocycle $[9,26]$, such triazolestyrene latex particles are potential candidate as a solid support for metal ion remediation in wastewater effluents.

Funding: The authors received no specific funding for this work.

Conflict of Interest: The authors declare that they have no conflict of interest.

\section{References}

1. Altava B, Burguete MI, Garcia-Verdugo E, Luis SV (2018) Chiral catalysts immobilized on achiral polymers: effect of the polymer support on the performance of the catalyst. Chem Soc Rev 47: 2722-2771. https://doi.org/10.1039/C7CS00734E

2. Aydın EB, Aydın M, Sezgintürk M K (2018) Highly sensitive electrochemical immunosensor based on polythiophene polymer with densely populated carboxyl groups as immobilization matrix for detection of interleukin $1 \beta$ in human serum and saliva. Chem Sen and Act B: 270: 18-27. https://doi.org/10.1016/j.snb.2018.05.014

3. Cho YS , Shin CH, Han S (2016) Dispersion polymerization of polystyrene particles Using Alcohol as Reaction Medium. Nanoscale Res Lett 11:46. https://doi.org/10.1186/s11671-016-1261-8

4. Elaissari A (2003) Colloidal Polymers: Synthesis and Characterization. CRC press.

5. Bell CA, Smith S V, Whittaker MR, Whittaker A K, GahanL R, MonteiroM J (2006) Surface-Functionalized Polymer Nanoparticles for Selective Sequestering of Heavy Metals. Adv Mater 18:582-586. https://doi.org/10.1002/adma.200501712

6. Huang C, Kobayashi H, Moritaka M, Okubo M (2017) Hollow Particles are Produced by the Burying of Sulfate End-Groups Inside Particles Prepared by Emulsion Polymerization of 
Styrene with Potassium Persulfate as Initiator in the Absence/Presence of Nonionic Emulsifier. Polym Chem 8: 6972-6980. https://doi.org/10.1039/C7PY01608E

7. Okubo M, Kobayashi H , Huang C, Miyanaga E, Suzuki T (2017) Water Absorption Behavior of Polystyrene Particles Prepared by Emulsion Polymerization with Nonionic Emulsifiers and Innovative Easy Synthesis of Hollow Particles. Langmuir 33 (14): 34683475. https:// doi.org/10.1021/acs.langmuir.7b00232

8. Trochimczuk AW, Kolarz BN (2000) Synthesis and chelating properties of resins with methylthiourea, guanylthiourea and dithiocarbamate groups. J Eur Polym 36: 2359-2363. https:// doi.org/10.1016/S0014-3057(00)00007-0

9. Lahmar H, Saidi-Besbes S, Elaissari A, Derdour A (2015) poly(1,2,3-triazole) Latex Particles: Synthesis and Chelating Properties. J Colloid Sci Biotech 4:1-7. https://doi.org/10.1166/jcsb.2015.1111

10. Denizli A, Kesenci K, Arica Y, Piskin E (2000) Dithiocarbamate-incorporated monosize polystyrene microspheres for selective removal of mercury ions. React Funct Polym 44: 235243. https://doi.org/10.1016/S1381-5148(99)00099-1

11. Dinu MV, Dragan ES (2008) Heavy metals adsorption on some iminodiacetate chelating resins as a function of the adsorption parameters. React Funct Polym 68: 1346-1354. https://doi.org/10.1016/j.reactfunctpolym.2008.06.011

12. Trochimczuk AW (1998) chelating resins with n-substituted diamides of malonic acid as ligands. J Eur Polym 11: 1657-1662. https:// doi.org/10.1016/S0014-3057(98)00018-4

13. Pan B, Pan B, Zhang W, Lv L, Zhang Q, Zheng S (2009) Development of polymeric and polymer-based hybrid adsorbents for pollutants removal from waters. J Chem Eng 151: 1929. https://doi.org/10.1016/j.cej.2009.02.036

14. Uzun L, Kara A, Tüzmen N, Karabakan A, Beşirli N, Denizli A (2006) Synthesis and Characterization of Poly(ethylene glycol dimethacrylate-1-vinyl-1,2,4-triazole) Copolymer

Beads for Heavy-Metal Removal. J Appl Polym Sci 102: 4276-4283. https://doi.org/ 10.1002/app.24830

15. Jakowski J, Huang J, Garashchuk S, LuoY, Hong K, Keum J, Sumpter BG (2017) Deuteration as a Means to Tune Crystallinity of Conducting Polymers. J Phys Chem Lett 8: 4333-4340. https://doi.org/10.1021/acs.jpclett.7b01803

16. White RP, Lipson JEG, Higgins JS (2010) Effect of Deuterium Substitution on the Physical Properties of Polymer Melts and Blends. Macromolecules 43: 4287-4293. https://doi.org/10.1021/ma902707u 
17. Shao M, Keum J, Chen J, He Y, Chen W, Browning JF, Jakowski J, Sumpter BG, Ivanov IN, Ma YZ, et al (2014) The Isotopic Effects of Deuteration on Optoelectronic Properties of Conducting Polymers. Nat Commun 5: 3180. https://doi.org/10.1038/ncomms4180

18. Duracher D, Sauzedde F, Elaissari A, Perrin A, Pichot C (1998) Cationic aminocontaining $\mathrm{N}$-isopropylacrylamide styrene copolymer latex particles: 1-Particle size and morphology vs. polymerization process. Colloid Polym Sci 276: 219-231. https://doi.org/10.1007/s003960050232

19. Ni H, Du Y, Ma G, Nagai M, Om S (2001) Mechanism of Soap-Free Emulsion Polymerization of Styrene and 4-Vinylpyridine: Characteristics of Reaction in the Monomer Phase, Aqueous Phase, and Their Interface. Macro 34 (19): 6577-6585. https:// doi.org/ 10.1021/ma010829d

20. Ho KM, Li WY, Wong CH et al (2010) Amphiphilic polymeric particles with core-shell nanostructures: Emulsion-based syntheses and potential applications. Colloid Polym Sci 288 (16):1503-1523. https://doi.org/10.1007/s00396-010-2276-9

21. Kawaguchi H, Hoshino F, Ohtsuka K (1986). Makromol Chem Rapid Commun 7: 109114. https://doi.org/10.1002/marc.1986.030070302

22. Shoaf GL, Poehlein GW (1991) Kinetics of Emulsion Copolymerization with Acrylic Acids. J Appl Polym Sci. 42: 1213-1237. https://doi.org/10.1002/app.1991.0704205067

23. Shoaf GL, Poehlein GW (1991) Solution and emulsion polymerization with partially neutralized methacrylic acid. J Appl Polym Sci 42:1239-1257.

24. Clouet G, Chaffanjon P (1990) rate constants in the free-radical polymerization of perdeuterated styrene. J Macromol Sci Chem. 27:193-212. http://doi.org/10.1080/00222339009351496

25. Chainey M, Hearn J, Wilkinson MC (1981) Preparation of Overcoated Polymer Latices by a 'Shot Growth' Technique. J the British polym. September:132-136.

http://doi.org/10.1002/pi.4980130310

26. Mokadem Z, Mekki S, Saidi-Besbes S, Agusti G, Elaissari A, Derdour A (2017) Triazole containing magnetic core-silica shell nanoparticles for $\mathrm{Pb}^{2+}, \mathrm{Cu}^{2+}$ and $\mathrm{Zn}^{2+}$ removal. J Arabian Chem. 10:1039-1051. http://doi.org/10.1016/j.arabjc.2016.12.008 


\section{Table and figure captions}

Table 1. Latex recipes for batch process

Table 2. Latex recipes for shot-growth process

Table 3. Results of surfactant-free batch polymerization of styrene with DEGTz and TEGTz

Table 4. Results of surfactant-free polymerization of perdeuterated styrene with DEGTz and TEGTz in batch and shot-growth conditions (Styrene $\mathrm{d}^{8}(3 \mathrm{~g})+$ triazolic Monomer $(0.2 \mathrm{~g})$ )

Scheme 1.Synthetic procedure of monomers DEGTz and TEGTz

Fig 1. TEM micrographs A) SDZ1, B) SDZ2, C) SDZ3, D) STZ1, E) STZ2

Fig 2. Evolution of particle size with polymerization time for PS, SDZ2 and STZ2 latexes.

Fig 3. Zeta potential of latexes prepared by batch polymerization of styrene with DEGTz and TEGTz as function of $\mathrm{pH}$

Fig 4. ${ }^{1} \mathrm{H}-\mathrm{NMR}$ spectra of a) DEGTz, b) $\mathrm{SDZ} 1$ in $\mathrm{CDCl}_{3}$ and c) in $\mathrm{D}_{2} \mathrm{O}$ (homopolymer)

Fig 5. TEM micrographs A) PSd, B) SdDZ, C), D) SdTZ, E) SSdDZ, F) SSdTZ

Fig 6. ${ }^{1} \mathrm{H}$ NMR spectra of $\mathrm{SdDZ}$ in a) $\mathrm{CDCl}_{3}$, b) $\mathrm{D}_{2} \mathrm{O}$; $\mathrm{SSdDZ}$ in c) $\mathrm{CDCl}_{3}$, d) $\mathrm{D}_{2} \mathrm{O}$ $\mathrm{m}, \mathrm{h}, \mathrm{c}$ refer to residual monomer, polytriazole homopolymer and copolymer respectively

Fig 7. Zeta potantiel of perdeuterated polystyrene particles functionalized with DEGTz and TEGTz monomers as a function of $\mathrm{pH}$. 